\title{
H-Net Book Reviews: Enhancing Scholarly Communication with Technology
}

\section{Eileen L. McGrath, Winifred Fordham Metz, and John B. Rutledge}

This article traces the development of the book reviews on $\mathrm{H}-\mathrm{Net}$ and focuses on features such as length, content, style, timeliness, and format, as well as the aims and expectations of $\mathrm{H}$-Net book review editors. A study was conducted comparing reviews appearing in a print journal with similar reviews published by an $\mathrm{H}-\mathrm{Net}$ network. The study also examines the academic status of the authors of electronic reviews and compares this to the authors of print reviews. Drawing on findings from the study, as well as interactions with faculty and scholars using the $\mathrm{H}$-Net resource, it is concluded that there are some significant differences between print reviews and e-reviews.

But this is an imperfect world, as actors, athletes, priests and Presidents soon discover. Writers have known this from the day they read their first review.

\section{- Thomas Fleming ${ }^{1}$}

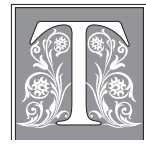

he urge to criticize what others have said or written is deepseated. Thus, book reviews have long been an element of scholarly communication. Most academic journals in nonscientific fields include book reviews. In the humanities, book reviews often occupy a third or more of a journal's pages. The reasons for writing reviews are myriad. Scholars often write reviews to participate in their discipline's dialogue, to keep their names before their peers, or simply to boost their number of publications. They read reviews to learn of new books as well as to see how their peers receive other scholars' ideas. Despite the pessimism in quotations such as the one above, each scholar harbors the hope that the world is not so imperfect and that his or her book will receive positive reviews in top-tier journals. Until recently, scholars looked to print journals to find a more perfect world, but now there is an alternative-the world of electronic

Eileen L. McGrath is the Collection Management Librarian in the North Carolina Collection, University of North Carolina at Chapel Hill; e-mail: levon@unc.edu. Winifred Fordham Metz is the Media Resources Librarian at the University of North Carolina at Chapel Hill; e-mail: freddie@email.unc.edu. John B. Rutledge is the Bibliographer, West European Resources, and Head of Humanities, Social Sciences, and West European Collection Development at the University of North Carolina at Chapel Hill; e-mail: jbr@email. unc.edu. 
communication. Has technology made this new world a more perfect one, or do the imperfections of the print world also exist in the one online?

Librarians have long been accustomed to consulting a wide range of reviewing sources, including scholarly journals, newspapers, general periodicals, and library journals. Many librarians read scholarly book reviews as an aid to selection and to follow the evolution of a discipline. During the past decade, the Internet also has become an important source of reviews. Internet reviews can be divided into two categories: those that originated in print but are published online either simultaneously or later and those that originate online. This later type of review, the born digital, or e-review, is a relatively new source of information, but how good is this source? Like so much else on the Web, Internet review sources tend to be written by and aimed at a general, rather than an academic, audience. However, there is one major source for scholarly reviews in the humanities - the $\mathrm{H}-\mathrm{Net}$ networks.

Currently, scholars, bibliographers, and subject specialist librarians consult $\mathrm{H}-\mathrm{Net}$ reviews. As a result of a recent decision by the Library of Congress, $\mathrm{H}$ Net reviews will become more widely known. In 2003, the library began to link records in its online catalog to $\mathrm{H}-\mathrm{Net}$ reviews. Already more than 6,000 titles in the Library of Congress online catalog have been linked to H-Net, and the library plans to add between one and two thousand links each year. ${ }^{2}$ This will increase the availability and the visibility of $\mathrm{H}-\mathrm{Net}$ reviews, but it also raises questions for librarians: Are these "born digital" reviews something wholly different from print reviews? And if so, how are they different? The present study evaluates $\mathrm{H}-\mathrm{Net}$ reviews, using both traditional criteria and criteria appropriate to electronic sources. Examining the context of $\mathrm{H}-\mathrm{Net}$ reviews and features of $\mathrm{H}-\mathrm{Net}$ reviews, it then compares a sample of $\mathrm{H}-\mathrm{Net}$ reviews to a set of print counterparts.

\section{The Development of $\mathrm{H}-\mathrm{Net}$}

$\mathrm{H}$-Net book reviews can hardly be considered separately from the parent institution, H-Net: Humanities and Social Sciences Online (H-Net). Formed in 1992 by Richard J. Jensen of the University of Illinois at Chicago, H-Net was a new venture in scholarly communication. Jensen and a few other historians saw that electronic communication offered possibilities for creating scholarly discussions not bound by the traditional barriers of geography, discipline, and status. H-Net seemed to be based on an idealistic and democratic vision, with Jensen and his colleagues setting out to provide an opportunity for a wide range of scholars to participate in discussions that previously had been too limited to the elites of the profession. Extending beyond the traditional model of senior scholars publishing in established print journals, H-Net provided a forum for teachers and scholars at smaller institutions, academics in isolated locations, and newly minted masters and Ph.D.s to discuss research interests, share pedagogical materials, and critique each other's work.

H-Net initially focused on providing a moderated forum that would foster both networking and the exchange of information. The first discussion lists were H-Urban and H-Women, along with a preexisting list for scholars of the Holocaust. ${ }^{3}$ As H-Net attracted the attention of scholars, the number of lists under the H-Net umbrella grew to twenty-one by the end of $1993 .{ }^{4} \mathrm{H}-\mathrm{Net}$ added new lists steadily throughout the 1990s so that when the decade ended, there were more than a hundred lists with 100,000 total subscribed readers. ${ }^{5}$ By 2003 , there 
were more than 150,000 subscribers. ${ }^{6}$ The standard national and topical varieties of history such as British history, Civil War history, and labor history were represented in some of the first lists. Expanding further into other areas of academia, new lists reflected specific interests such as area studies, geography, political science, religion, and pedagogy.

Along with this growth came changes in structure, funding, leadership, and content. Originally, Jensen worked informally with his associates and graduate students. H-Net operated with volunteer staff, computer facilities at the University of Illinois at Chicago, and funding from the National Endowment for the $\mathrm{Hu}$ manities. As the number of lists and subscribers increased, Jensen recruited other scholars to screen subscribers, moderate lists, and solicit and edit reviews. In 1994, a formal governance system was created, including an executive committee with Jensen serving as the first executive director. As this governance structure was being created, it became apparent that the previous level of institutional and grant-funded support was inadequate for the growing organization. When Michigan State University made a generous offer of support, H-Net accepted the offer and moved its offices to the Michigan State campus in 1995. Shortly after the relocation, a changing of the guard occurred when Mark Lawrence Kornbluh of Michigan State University defeated Richard Jensen in the 1997 election for executive director. Under Kornbluh's leadership, the new guard improved the structural underpinnings of H-Net by developing a constitution and bylaws. In addition, they strengthened the financial and administrative support at H-Net's headquarters at MATRIX, the Center for Humane Arts, Letters, and Social Sciences Online at Michigan State University.

\section{Books Reviews on H-Net}

Although discussion remains the primary focus of H-Net lists, during the 1990s most lists added other features such as conference announcements, job listings, syllabi, and reviews of books and media. The book reviews on H-Net are the focus of this article. The earliest reviews archived on H-Net were published on H-Law in August 1993. Only H-Law and H-CivWar published reviews during H-Net's first year of operation. In 1994, a dozen book reviews were published on several lists, but reviews did not become common on H-Net's discussion lists until 1995. That was the year that reviews became a prominent and regular feature on many lists. It also was the year that $\mathrm{H}-\mathrm{Net}$ began to gather together the reviews from all the discussion lists into a separate list entitled H-Review. Mark Lawrence Kornbluh and James Sleight were-and remain - the managing editor and assistant editor of the H-Net Review Project, now called $\mathrm{H}-\mathrm{Net}$ Reviews. Subscribers to H-Net Reviews receive all of the book reviews published by $\mathrm{H}-\mathrm{Net}$ regardless of the list on which the review originated. The H-Net Reviews site also archives the reviews, which then can be searched by author, title, publisher, ISBN, LC card number, reviewer name, date of review, list that published the review, and keywords. Four thousand reviews had been archived by 2000, with new reviews being added at the rate of about a thousand a year.

The reviews button is one of the most popular links on the H-Net home page. ${ }^{7}$ About half of the lists offer e-reviews as a standard element of their operations. Of the 138 lists operating in the fall of 2003, forty-seven posted new reviews during November and December of that year. The number of reviews published per list varied; only seventeen lists published reviews in both November and December. The lists with the most reviews 
were generally those that focused on established historical topics such as British history, German history, the American Civil War, and Latin America. Other lists focusing on younger subdisciplines such as urban history, environmental history, and women's history also posted large numbers of reviews.

Where the publishing universe is not large, fewer reviews appear because there are fewer titles to review. The discussion lists devoted to individual states within the United States reflect this. There are twelve such lists, but only seven have archived reviews. ${ }^{8}$ Even the active state lists may post only a handful of reviews, presumably because in any given year only a few dozen books might be published that deal with some aspect of the state's history. In the fall of 2003, only the lists for California, Florida, Indiana, and Tennessee distributed reviews, and only $\mathrm{H}$-California and H-Florida distributed reviews more than once.

The administrative structure of each $\mathrm{H}$ Net network varies somewhat. Most have an advisory board and one or more "list editors." Many have one or more review editors. The editor plays a crucial role in the development of the book review enterprise. Without a dedicated and persevering editor to champion and manage the book review feature, it will not grow and cannot sustain itself. Idealism and the possibilities of the electronic medium may initially inspire a review editor, but idealism must eventually coalesce into a work schedule. One book review editor stated that she hoped to review "every single book published in English in the subject field." ${ }^{\prime}$ This is representative of the high ideals of the undertaking. The number of publications in active fields surely outstrips the best efforts of others scholars to consider them all. Only a portion of total book production can be reviewed.

\section{Features of $\mathrm{H}-\mathrm{Net}$ Reviews}

Much information is not free. Many databases of interest to scholars and researchers are proprietary, carefully guarded and accessible only to those persons ("library patrons") whose IP address certifies them as credentialed. By contrast, H-Net reviews are a free public service, accessible to anyone with Internet access. The $\mathrm{H}-\mathrm{Net}$ site is easy to use. Reviews can be found by either using the Reviews button on the H-Net home page or accessing reviews through a specific subject list. In either case, reviews can be searched by keyword, author, title, publisher, ISBN, LC card number, reviewer name, date of review, or list that published the review. $\mathrm{H}-\mathrm{Net}$ reviews also can be found through many search engines. Google will readily retrieve an H-Net review for any known title; simply search for the word "H-Net" and the title of the book. The result should be a direct hit for the H-Net review.

The automatic delivery service of reviews is an attractive feature of $\mathrm{H}-\mathrm{Net}$. Scholars who subscribe to H-Net lists are not forced to search widely for book reviews in a narrowly prescribed field. H-Net posts its reviews to the subscriber's e-mail address, making them readily accessible wherever a subscriber has access to his or her e-mail account. The usefulness of the reviews depends on how carefully a reader has entered his or her subscriptions. When one subscribes to H-Net Reviews, all of the reviews posted to any of the discussion lists are sent to the subscriber. If one subscribes to just an individual discussion list, such as H-Italy, only the reviews originating on that list are sent. The choice is the subscriber's. H-Net can be used as one might use a general review source such as The American Historical Review, or it can be set up to function more like a very focused journal or a customized current awareness service. 
The electronic format allows for the addition of hot links. Visual materials such as animation or video clips of historic footage also can be added. However, reviewers almost never do this. The reasons for this are varied. One book review editor cited the worldwide subscriber base as a reason that the reviews on her list rarely had hot links. Thinking that subscribers would have a wide range of technological capacity, she did not want to send out reviews that would not be equally useful to all the subscribers. ${ }^{10} \mathrm{~A}$ book review editor for a different $\mathrm{H}$-Net list thought that reviewers were concerned that $\mathrm{H}$-Net reviews be seen as having the same importance as a print review, so they chose not to include things in their reviews that would not be found in a print journal. ${ }^{11}$ Another reason might be that the book review must focus on the book itself. References to things other than the book under review fall into the category of the extraneous; they are inappropriate in a genre that treasures brevity and succinctness.

Because book reviews posted in the $\mathrm{H}$-Net groups always carry the e-mail address of the author, one can assume that there is some degree of informal correspondence between readers and reviewers. The degree of interaction seems to vary from one discussion group to another. Only a handful of instances of public exchanges between reviewer and author or reviewer and reader have been found. In order to spark discussion, some lists, such as H-South, will arrange an exchange between the review and the author. The book review editor will announce these paired essays ahead of time. Undoubtedly, the editor hopes to provoke a wider discussion. The results of these efforts have been mixed, in part because arranged discussions originating from book reviews compete with spontaneous discussions that arise from the questions and opinions of the subscribers.
Both scholars and librarians have hoped that e-reviews could shorten the much-lamented lag time between the publication of a book and the appearance of reviews. The technology can increase the timeliness of reviews as electronic publication is accomplished without the time-consuming steps of printing, binding, and mailing. The record of H-Net reviews shows that this is true. Table 1 shows the difference between publication date and review date for a sample of reviews distributed by H-Italy between 1996 and May 2003. More than half of the books reviewed (52.4\%) were reviewed in the year of their publication or the following year. Almost nine in ten of the reviews $(85.7 \%)$ were for books published within the current and two previous calendar years. As the H-Italy sample was small and included reviews from the list's early days, a more current set of reviews also was examined. Table 2 shows the difference between publication date and review date for all 106 English-language reviews delivered via e-mail between May 1 and June 15, 2003. These reviews came from a variety of discussion lists rather than a single list. The timeliness of the reviews was impressive: almost two-thirds of the reviews $(64.1 \%)$ were for books published

\begin{tabular}{|c|c|c|}
\hline \multicolumn{3}{|c|}{$\begin{array}{c}\text { TABLE } 1 \\
\text { Sample of H-Italy Reviews, } \\
\text { 1996-2003 }(\mathrm{N}=21)\end{array}$} \\
\hline & No. & $(\%)$ \\
\hline $\begin{array}{l}\text { Year of review and book } \\
\text { publication date were the } \\
\text { same: }\end{array}$ & 2 & $(9.5 \%)$ \\
\hline $\begin{array}{l}\text { Review appeared one year } \\
\text { after publication date: }\end{array}$ & 9 & $(42.9 \%)$ \\
\hline $\begin{array}{l}\text { Review appeared two years } \\
\text { after publication date: }\end{array}$ & 7 & $(33.3 \%)$ \\
\hline $\begin{array}{l}\text { Review appeared three } \\
\text { years after publication date: }\end{array}$ & 1 & $(4.8 \%)$ \\
\hline $\begin{array}{l}\text { Review appeared four years } \\
\text { after publication date: }\end{array}$ & 2 & $(9.5 \%)$ \\
\hline
\end{tabular}




\begin{tabular}{|l|r|c|}
\hline \multicolumn{3}{|c|}{ TABLE 2} \\
2003 (N = 106) \\
\hline \multicolumn{3}{|c|}{ H-Review Reviews, May-June 15, } \\
\hline \hline & No. & $\mathbf{( \% )}$ \\
\hline $\begin{array}{l}\text { Year of review and book pub- } \\
\text { lication date were the same: }\end{array}$ & 3 & $(2.8 \%)$ \\
\hline $\begin{array}{l}\text { Review appeared one year } \\
\text { after publication date: }\end{array}$ & 65 & $(61.3 \%)$ \\
\hline $\begin{array}{l}\text { Review appeared two years } \\
\text { after publication date: }\end{array}$ & 25 & $(23.6 \%)$ \\
\hline $\begin{array}{l}\text { Review appeared three years } \\
\text { after publication date: }\end{array}$ & 8 & $(7.5 \%)$ \\
\hline $\begin{array}{l}\text { Review appeared four years } \\
\text { after publication date: }\end{array}$ & 3 & $(2.8 \%)$ \\
\hline $\begin{array}{l}\text { Review appeared more than } \\
\text { four years after publication } \\
\text { date: }\end{array}$ & 2 & $(1.9 \%)$ \\
\hline
\end{tabular}

in 2002 or 2003; almost nine in ten reviews $(87.7 \%)$ were for books published in 2003 or the previous two calendar years.

As good as these figures are, they will still be a disappointment to some. Book reviewing is a multistep process. First, books must be identified for review and qualified reviewers found. Next, books are sent to the reviewers, who then must read and ponder the books before writing their reviews. What technology has not been able to abbreviate is the "think time" required by scholars to read a book and write a credible review of it. Reviewers have to fit reviews into their professional schedules. Deadlines are missed for e-reviews, just as they are for print journals. ${ }^{12}$ Then, an editor must evaluate each review. Any back-and-forth between editor and reviewer can further delay publication of the review. Although technology can speed the distribution of reviews, it has not radically altered the way reviews are created..$^{13}$

\section{Comparison to Print Reviews, or How E-reviews Differ}

To see whether e-reviews differ substantially from print reviews, a set of reviews from the $\mathrm{H}$-South listserv was compared to reviews published in The Journal of Southern History (JoSH). An established and respected journal, JoSH has the same subject focus as $\mathrm{H}$ South. H-South was chosen because of a professional interest in this particular listserv in addition to its being a reasonably active list for discussions, announcements, and reviews. During 2002, H-South posted reviews of sixty-seven books. Using them as the sample, these H-South reviews were matched to reviews of the same titles in $\mathrm{JoSH}$. Fifty-one of the titles reviewed in $\mathrm{H}$-South were also reviewed in $\mathrm{JoSH}$ between the January 2002 and the August 2003 issues. ${ }^{14}$ These two sets of reviews then were examined to see if there were discernible differences in the reviews themselves and the reviewer characteristics, as well as any judgments made about the books being reviewed.

\section{Choice of Books to Review}

As a newer and less traditional organization, $\mathrm{H}$-South might be expected to review books that are outside the mainstream of academic publishing and, perhaps, titles missed or ignored by the establishment. This was not the case in 2002. The overwhelming majority of books reviewed in $\mathrm{H}$-South (fifty-one of sixty-seven titles) also were reviewed in JoSH. University presses published fifteen of the sixteen titles reviewed in $\mathrm{H}$-South that were not reviewed in JoSH. The one remaining title was the product of a respected commercial publisher. In its choice of books to review, H-South appears to take a traditional approach rather than presenting a more diverse or unconventional selection of books.

One reason for the conservative selection of books reviewed may be that $\mathrm{H}$-South has not built a sufficiently large stable of reviewers. The editors may have 


\begin{tabular}{|l|r|c|}
\hline \multicolumn{3}{|c|}{ TABLE 3} \\
Years Since Ph. D. Degree of \\
H-South Reviewers (N = 66) \\
\hline \hline \multicolumn{2}{|c|}{ No. } & $\mathbf{( \% )}$ \\
\hline Graduate student or ABD: & 25 & $(39.7 \%)$ \\
\hline $\begin{array}{l}\text { Less than 10 years since } \\
\text { Ph.D. granted: }\end{array}$ & 28 & $(44.4 \%)$ \\
\hline $\begin{array}{l}\text { 10-20 years since degree } \\
\text { granted: }\end{array}$ & 6 & $(9.5 \%)$ \\
\hline 20+ years since degree: & 4 & $(6.3 \%)$ \\
\hline $\begin{array}{l}\text { Unable to determine } \\
\text { degree status: }\end{array}$ & 3 & \\
\hline (Percentages based on 63 known cases) \\
\hline
\end{tabular}

decided to use their limited number of reviewers to focus on the books that their audience is most likely to be interested in-books from academic presses. In contrast, JoSH has a larger number of reviewers. H-South published sixty-seven reviews in 2002, whereas JoSH published 309 reviews. The majority of the books reviewed in $\mathrm{JoSH}$ were also academic press titles, but 20 percent of the titles reviewed were from trade presses or noncommercial publishers such as historical societies. The larger number of reviews and available reviewers allows the editors of $\mathrm{JoSH}$ to review a wide range of books on Southern history.

\section{Academic Status of Reviewers}

Who are the authors of e-reviews? How do their credentials compare with those of the reviewers in print journals? To answer these questions, the academic status of each contributor of a review to H-South in 2002 and of the reviewers of the same books in JoSH was investigated. When the rank of the reviewer or the person's academic affiliation was not provided in the review itself, the reviewer was traced through institutional Web sites. In a few cases, the reviewer was contacted via email. The number of years each person had been in the field was established by using Digital Dissertations by ProQuest to find the year each person received his or her doctoral degree. The sample size was sixty-six reviewers for $\mathrm{H}$-South and fifty-one for $\mathrm{JoSH} .{ }^{15}$

While the authors expected that newer scholars wrote $\mathrm{H}$-South reviews, it was surprising to find that graduate students or ABDs wrote almost 40 percent of $\mathrm{H}$ South reviews in the sample. (See tables 3 and 4.) Junior faculty (defined as persons who were awarded their doctorate less than ten years before the date of the review) wrote another 44.4 percent. Only a small percentage $(15.8 \%)$ of the H-South reviews were written by "senior faculty," persons who were ten or more years into their careers. Almost 26 percent of the $\mathrm{H}$ South reviewers held the rank of assistant professor. Nearly 13 percent ranked as associate professors, and just less than 10 percent had attained full professor status. Almost 10 percent held nonfaculty appointments or were independent scholars. The status of four reviewers could not be determined.

There were significant differences between the reviewers for $\mathrm{H}$-South and $\mathrm{JoSH}$ reviewers. (See tables 5 and 6.) Only two

\begin{tabular}{|c|c|c|}
\hline \multicolumn{3}{|c|}{$\begin{array}{c}\text { TABLE } 4 \\
\text { Academic Rank of H-South } \\
\text { Reviewers }(\mathrm{N}=66)\end{array}$} \\
\hline & No. & $(\%)$ \\
\hline Graduate student: & 15 & $(24.2 \%)$ \\
\hline Adjunct or visiting: & 11 & $(17.7 \%)$ \\
\hline Assistant professor: & 16 & $(25.8 \%)$ \\
\hline Associate professor: & 8 & $(12.9 \%)$ \\
\hline Full professor: & 6 & $(9.7 \%)$ \\
\hline Emeritus: & 0 & \\
\hline Nonfaculty appointment: & 5 & $(8 \%)$ \\
\hline Independent scholar: & 1 & $(1.6 \%)$ \\
\hline $\begin{array}{l}\text { Unable to determine } \\
\text { appointment: }\end{array}$ & 4 & \\
\hline (Percentages based on 62 & ses & \\
\hline
\end{tabular}


of the JoSH reviewers were graduate students or ABDs. Almost one-quarter (23.5\%) of the JoSH reviewers were junior faculty; however, a far greater number were established academics. Slightly more than 37 percent of $\mathrm{JoSH}$ reviewers had ten to twenty years of professional experience and another 35.5 percent had more than twenty years. These seasoned scholars wrote more than two-thirds of the JoSH reviews.

Comparing the distribution of academic ranks dramatically reflects the difference between the two reviewer groups. Only one JoSH reviewer was an adjunct or visiting professor, as compared to eleven $\mathrm{H}-\mathrm{Net}$ reviewers in this category. (See tables 4 and 6.) Whereas 25.8 percent of $\mathrm{H}$-South reviewers were assistant professors, only 9.8 percent of $\mathrm{JoSH}$ reviewers were assistants. The majority of reviewers for JoSH were established academics: 33.3 percent were associate professors and 39.2 percent were full professors. Three emeritus professors also contributed reviews. Whereas over two-thirds $(67.7 \%)$ of $\mathrm{H}$-South reviewers were graduate students, adjuncts, visiting, or assistant professors, 78.4 percent of $\mathrm{JoSH}$ reviewers were associate, full, or emeritus professors.

\begin{tabular}{|l|r|r|}
\hline \multicolumn{3}{|c|}{ TABLE 6 } \\
Academic Rank of Journal of \\
Southern History Reviewers \\
(N = 51) \\
\hline \hline \multicolumn{3}{|c|}{} \\
\hline Graduate student: & 2 & $(3.9 \%)$ \\
\hline Adjunct or visiting: & 1 & $(1.9 \%)$ \\
\hline Assistant professor: & 5 & $(9.8 \%)$ \\
\hline Associate professor: & 17 & $(33.3 \%)$ \\
\hline Full professor: & 20 & $(39.2 \%)$ \\
\hline Emeritus: & 3 & $(5.9 \%)$ \\
\hline Nonfaculty appointment: & 2 & $(3.9 \%)$ \\
\hline Independent scholar: & 1 & $(1.9 \%)$ \\
\hline
\end{tabular}

\begin{tabular}{|l|r|c|}
\hline \multicolumn{3}{|c|}{ TABLE 5 } \\
Years Since Ph. D. Degree of \\
Journal of Southern History \\
Reviewers (N = 51) \\
\hline \hline \multicolumn{2}{|c|}{ No. } & $\mathbf{( \% )}$ \\
\hline Graduate student or ABD: & 2 & $(3.9 \%)$ \\
\hline $\begin{array}{l}\text { Less than 10 years since } \\
\text { Ph.D. granted: }\end{array}$ & 12 & $(23.5 \%)$ \\
\hline $\begin{array}{l}\text { 10-20 years since degree } \\
\text { granted: }\end{array}$ & 19 & $(37.3 \%)$ \\
\hline 20+ years since degree: & 18 & $(35.3 \%)$ \\
\hline
\end{tabular}

Two very different groups of academics populate the reviewer stables of these sources. The H-South reviewers were younger, less established, and somewhat more itinerant. The JoSH reviewers were older, more experienced, and higher up in the academic hierarchy. Do the differences in reviewer characteristics influence the style, tone, and content of the reviews themselves?

\section{A Difference in Evaluations?}

How a reviewer's experience and academic status might affect what he or she wrote was considered prior to examining the reviews. Would younger scholars be more critical in their book reviews? Would they be more likely to question the assumptions and scholarship of the authors whose works they review-young Turks attacking the Establishment? Or would the opposite be true? Would younger scholars be cautious, even generous, in their reviews so as to avoid making enemies of people whose acceptance and respect they might need later in their careers? An examination of the reviews showed that neither theory was correct.

The methodology developed by Matthew L. Jordy, Eileen L. McGrath, and John B. Rutledge was used to help address the question of whether e-reviews are more positive or more critical than print reviews. ${ }^{16}$ These authors recognized 


\begin{tabular}{|l|r|c|}
\hline \multicolumn{3}{|c|}{$\begin{array}{c}\text { TABLE 7 } \\
\text { H-South Evaluations of Quality } \\
\\
\end{array}$} \\
\hline & No. & $\mathbf{5 1})$ \\
\hline \hline Category 1: & 1 & $(\mathbf{\%})$ \\
\hline Category 2: & 17 & $(33.3 \%$ of the reviews $)$ \\
\hline Category 3: & 28 & $(54.9 \%$ of the reviews $)$ \\
\hline Category 4: & 3 & $(5.9 \%$ of the reviews $)$ \\
\hline Category 0: & 2 & $(3.9 \%$ of the reviews $)$ \\
\hline
\end{tabular}

that although most book reviews tend to be positive, they exhibit different degrees of enthusiasm, and that a discerning reader can detect these meaningful differences. Jordy, McGrath, and Rutledge established a five-tiered ranking system for analyzing reviews. The first category is for the truly outstanding book; one on which the reviewer lavishes praise. A category one book is a work likely to set a new standard in its field. The second category is for very good books, ones that receive much praise but also contain some flaws. Average books belong in the third category. The fourth category is for books that receive an overwhelmingly negative review overall. The final category (Category 0 ) is for those reviews in which the reviewer does not clearly indicate the book's value. Often these reviews are far more descriptive than evaluative.

The reviews in JoSH and $\mathrm{H}$-South concur to a remarkable degree in their assessment of quality. (See tables 7 and 8.) Both reviewer groups were guarded in assigning the highest rating to a book. In each set of reviews, only one book was judged to be an outstanding work. The two groups also panned the same number of books - just three. As might be predicted, the majority of each set of reviews fell solidly in the middle categories. Just over 88 percent of the H-South reviews were either Category 2 or 3, whereas 92.1 percent of the $\mathrm{JoSH}$ reviews were in these two middle categories. A closer examination of the figures might lead to the conclusion that $\mathrm{H}$-South reviewers were somewhat harsher judges because they rated only one-third of the books as "very good" (Category 2), as compared to JoSH reviewers who rated 39.2 percent of the books as the same category. However, the difference is not overly compelling and it should be noted that the $\mathrm{H}$-South sample contains two reviews in Category 0. Neither of these Category 0 reviews contained enough evaluative prose to determine the reviewer's opinion of the book. If those two reviews had been written more clearly, the number of H-South Category 2 reviews might have more closely matched those from JoSH. With this in mind, the authors concluded that there is no major difference in the harshness of the two groups of reviewers. What may be seen, instead, is an underlying consensus among historians of the American South as to what makes a good scholarly monograph.

\section{Length}

Although the two reviewer groups tended to assign similar values to books, the two sets of reviews displayed significant differences. The most obvious difference was in length. Some of the H-Net groups impose "page limits" on reviewers; others do not. Based on the research, it appears that e-reviews are significantly longer

\begin{tabular}{|l|r|c|}
\hline \multicolumn{3}{|c|}{ TABLE 8 } \\
Journal of Southern History \\
Evaluations of Quality (N = 51)
\end{tabular}


than print reviews. A random sample of 32 reviews from 309 reviews published in JoSH in 2002 was drawn. The longest review in the sample was 994 words and the shortest was 318. Most of the reviews contained 450 to 600 words, with an average length of 565 . This contrasts strongly with the 2002 reviews on H-South. None of the thirty-two randomly selected reviews published on $\mathrm{H}$-South in 2002 were under a thousand words. The shortest review was 1,056 words and the longest was 3,492 . Eighty percent of the reviews were between one and two thousand words. The average length was 1,780 words, almost three times the average length of the reviews in the JoSH sample. It appears that $\mathrm{H}$-South reviewers, presumably with editorial permission, take advantage of the unlimited space available in an online forum to describe the contents and report the arguments of a book more fully than they might be able to in print.

Reading through the H-South reviews, the authors were struck not only by the length of the reviews, but also by the number of reviews that detailed the contents of the book chapter by chapter. Reading an e-review was very much like reading a synopsis or a linear rehearsal of the arguments, findings, and overall content of the book. In some cases, the evaluative function of a book review seemed subordinate to the reporting function. Although only two of the reviews in the $\mathrm{H}$-South sample were so oblique that they could not be assigned to a category, at least a dozen others required very close reading to be certain of the reviewer's opinion. Some readers will find these long, detailed, but essentially descriptive, reviews valuable. A bibliographer with responsibility for a focused collection will find the H-Net-type of review most helpful. Does a monograph on the late twentieth-century rise of the Republican Party in the South include a chapter on
Jesse Helms? Does a book on the development of stock car racing include a state-by-state listing of the earliest commercial tracks? A bibliographer is more likely to find the answers to these types of questions in a review in $\mathrm{H}-\mathrm{Net}$ than in a printed journal review. However, mere description falls short of the intellectual dialogue necessary for the education of the discipline.

The chief advantage of reviews such as those examined on H-Net is that librarians and scholars can get a good sense of what the book being reviewed contains. The disadvantage is that reporting about content can replace a genuinely critical evaluation. When a librarian is searching for the best book on a topic, or a scholar needs a good book to recommend to a class, reading printed journal reviews may be a better strategy than reading $\mathrm{H}$-Net reviews. The convenience of electronically delivered, easily stored e-reviews may be canceled out in some instances by the excessive length of some reviews. Surely, there is a limit to how much text readers are willing to read in a book review. If the long review is also bland and lacks a critical assessment of the book, it may be of limited usefulness. By convention, a book review is a terse, tightly constructed and condensed form of communication. Editors of print journals have long known this and have perfected the form. E-reviews are still a relatively new variation on academic book reviews. E-review writers and editors are still finding their way to the best form. Who better to help perfect the form than the scholars who use H-Net? In describing how important H-Net is for him, one German historian said that he is training his students to write e-reviews. H-Net reviews have proved their usefulness to this younger scholar, and he is investing energy in teaching the next generation how to create them. 


\section{Conclusions}

The actual effect of an academic book review can only be measured imperfectly. Book reviews may or may not be marshaled as evidence in an academic's bid for tenure, a raise, or status within the guild. Both electronic and print reviews help the academy assess new works and determine whether they will be considered a contribution to the field. In this way, $\mathrm{H}-\mathrm{Net}$ reviews surely help influence the scholarly debate. On the whole, it cannot be denied that scholarly communication has been enhanced by $\mathrm{H}-\mathrm{Net}$ reviews. At the same time, it must be admitted that the relatively junior status of the reviewers themselves limits their authoritativeness for some purposes.

Reviews of academic books do little to influence sales to libraries that rely on approval plans for most of their acquisitions. Selectors at libraries that build their collections through title-by-title selection always hope for new, reliable review sources. For these librarians, $\mathrm{H}$ Net reviews are a welcome development. The around-the-clock availability, search options, promptness, and detailed nature of the reviews make $\mathrm{H}-\mathrm{Net}$ reviews a useful tool. H-Net could improve its value to librarians by including books from a wider range of publishers than those found in the H-South sample.
Opinions expressed on H-Net lists and in their reviews may affect which books are chosen for classroom use and, ultimately, for dissemination to students through lectures. The H-Net reviews often contain practical hints for scholars, including when the book could be used with undergraduates and for what courses it might be most appropriate. This is useful information not just for faculty, but also for librarians working with faculty on course reading lists and for reference staff providing guidance to individual students.

In examining $\mathrm{H}-\mathrm{Net}$ reviews, it can be seen that they differ from their print cousins in several significant ways; namely, in form and in content. Whether this will continue to be the case is uncertain, and so a cautionary note is necessary. $\mathrm{H}-\mathrm{Net}$ reviews are still in evolution. Even though potential differences such as hot links and reader-response events have not become common, H-Net reviews still bear some striking dissimilarities to traditional academic print book reviews at this time. It may be too early to tell whether e-reviews will diverge even further from print and become a distinct form of their own or whether they will ultimately adhere more closely to traditional norms and practices, but it is certain that they are becoming more important to younger scholars due to their ease of access, approachable form, and "searchability."

\section{Notes}

1. Thomas Fleming, "The War between Writers and Reviewers," New York Times Book Review, 6 January 1985, p. 3.

2. See http://www.loc.gov/catdir/beat/hnet.html.

3. Mark Lawrence Kornbluh and Peter Knupfer, "H-Net Ten Years On: Usage, Impact, and the Problem of Professionalization in New Media." Presented at the annual conference of the American Historical Association, Jan. 2003. Not paginated. Available online at

http://www.h-net.org/aha/2003/kornbluh_knupfer.htm. (Accessed 16 February 2004).

4. James P. Niessen, "H-Net and the Republic of Letters: New Models of Scholarly Communication: A Presentation at the International Booksellers and Librarians Centre, Frankfurt Book Fair, October 16, 1999" (rev. May 2000). Not paginated. Available online at http://www.stub.unifrankfurt.de/messe/proceedings/niessen.doc. (Accessed June 2003).

5. Ibid.

6. Kornbluh and Knupfer, "H-Net Ten Years On." 
7. Niessen, "H-Net and the Republic of Letters."

8. As of August 2003, the state lists were California, Florida, Illinois, Indiana, Iowa, Louisiana, Maryland, Michigan, New Mexico, Ohio, Tennessee, and Texas.

9. Susan Boettcher, editor of H-German, e-mail message to author, June 17, 2003. A survey of moderators and review editors of the various H-Net lists would be an interesting document and needs to be the object of a future investigation. In the case of the present study, the authors relied on e-mail contact with a small number of editors. Informal questions were presented to the first editor contacted. The initial list of questions was subsequently refined and sent to two other editors. Choice of contact persons was determined, in part, by prior association or simply by accessibility of the editor. An important feature of the "new medium" is that H-Net editors are at once more present and more accessible in H-Net reviews than is the case with print publications.

10. Stacy A. Cordery, review editor of H-Women, e-mail message to author, Aug. 13, 2003.

11. Susan Boettcher, e-mail message, June 17, 2003.

12. Ibid.

13. The administrative and postage costs related to reviewing have begun to strain the resources of H-Net. In an attempt to ease this financial burden, H-Net made an unprecedented request in April 2004, asking for donations from its subscribers. The organization also entered into a partner program with online booksellers Powell's, Barnes \& Noble, Amazon, and Amazon Germany so that $\mathrm{H}$-Net will receive royalties when buyers move from $\mathrm{H}-\mathrm{Net}$ to a purchase from one of these booksellers.

14. Research for this paper was conducted during the summer and fall of 2003.

15. One H-South reviewer contributed a joint review of two titles.

16. Matthew L. Jordy, Eileen L. McGrath, and John B. Rutledge, "Book Reviews as a Tool for Assessing Publisher Reputation," College E Research Libraries 60 (Mar. 1999): 132-42.

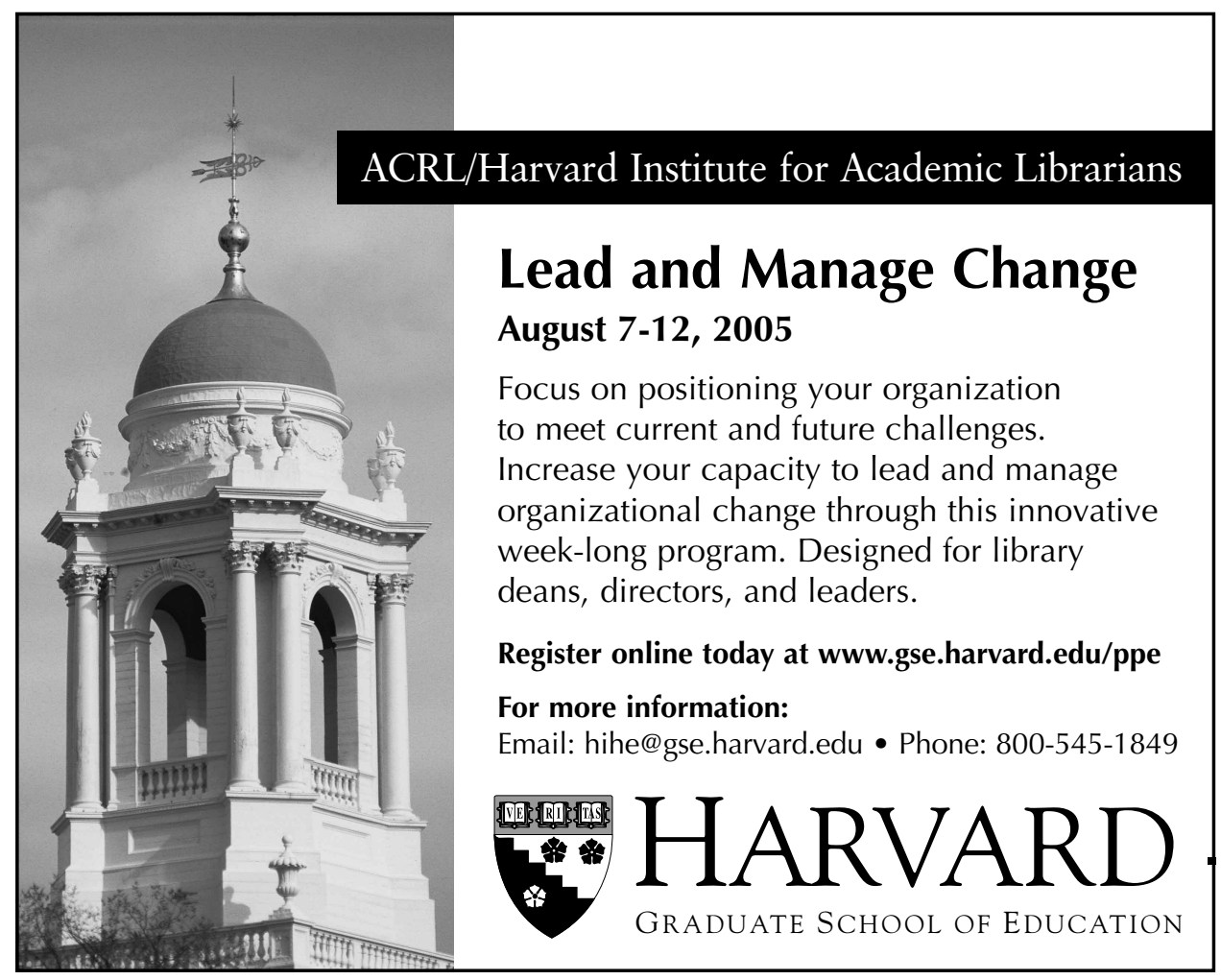

